\title{
Familial congenital heart block and hydrops fetalis
}

\author{
R W I COOKE, J W METTAU, A W VAN CAPPELLE, AND V H DE VILLENEUVE
}

Sophia Children's Hospital, Erasmus University, Rotterdam, The Netherlands

SUMMARY Two siblings were born with congenital heart block, and one suffered from severe hydrops fetalis, although maintaining a higher heart rate than the other. The association of hydrops fetalis with disorders of cardiac rhythm is unlikely to be simply a manifestation of congestive cardiac failure in the fetus.

Familial congenital heart block is a rare clinical entity. Two siblings with this disorder are described, one of whom suffered severe hydrops fetalis.

\section{Case reports}

Case 1. A 26 -year-old mother, para, $0+1$, was noticed to have a fetal bradycardia at 22 weeks' gestation. She had mild aortic stenosis and was being treated during pregnancy with prophylactic penicillin and digoxin. At 41 weeks she delivered a $3230-\mathrm{g}$ boy with a placenta weighing $520 \mathrm{~g}$. No birth asphyxia occurred, but the infant's heart rate was only 35 per minute. The liver was palpable $2 \mathrm{~cm}$ below the costal margin, and a grade $2 / 6$ precordial ejection murmur was audible. An ECG showed complete atrioventricular block with an atrial rate of 130 per minute. Chest $x$-ray at a few hours of life showed a cardiothoracic ratio of $66 \%$ and congested lung fields. Haemoglobin (Hb) was $23 \mathrm{~g} / \mathrm{dl}$, Coombs's test negative. Digoxin levels were insignificant.

There was clinical deterioration in the first few hours of life, with gross hepatic enlargement and signs of low cardiac output, requiring the placement of a transvenous pacing catheter. Pacing at 120 /minute at $2 \mathrm{~mA}$ produced immediate clinical improvement. At 48 hours, a spontaneous rhythm of $60 /$ minute was noted when pacing was stopped, and the catheter was removed. Subsequent progress was uneventful, and at age 3 years development is normal. His heart rate varies between 60 and 90 per minute, and the ECG shows complete A-V block. Chest $x$-ray shows left ventricular hypertrophy. He has no symptoms.

Case 2. The same mother delivered a baby girl 3 years later at 34 weeks' gestation. Fetal bradycardia had been noted from 28 weeks' gestation, and realtime 2-dimensional echo-examination showed signs of hydrops fetalis with hydrothorax, and enlargement of the heart and liver. The infant weighed $2830 \mathrm{~g}$ at birth and the placenta was described as 'thickened'. Immediate resuscitation was required at birth. Hepatomegaly, gross oedema, and ascites were present. Abdominal paracentesis drained $480 \mathrm{ml}$ ascitic fluid $(19.5 \mathrm{~g} / 1$ protein) before adequate ventilation could be achieved. The heart rate was fixed at 70 per minute. Hb was $20.8 \mathrm{~g} / \mathrm{dl}$ and Coombs's test negative. The urine contained no protein. She was ventilated for 6 hours, and later treated with CPAP until 24 hours of age when she was able to breathe air spontaneously. M-mode and 2-dimensional echocardiography showed a normal cardiac anatomy. After loss of oedema fluid, she weighed $1900 \mathrm{~g}$ on day 4 . Heart rate varied between 80 and 100 per minute and the ECG showed complete A-V block. Further progress was complicated by feeding difficulties ascribed to prematurity, and a single episode of congestive heart failure at 3 months was treated with frusemide. At age 4 months development appears normal.

\section{Discussion}

Familial heart block was first described by Morquio. ${ }^{1}$ It has occasionally been reported since. Michaelsson and Engle, ${ }^{2}$ in a review of congenital heart block, found an incidence of 1 per 20000 livebirths. Of the 599 infants reviewed, 34 had affected siblings, $30 \%$ also had an associated congenital cardiac anomaly, usually 'corrected' transposition of the great vessels. It has been suggested that familial heart block is due to localised degeneration or congenital absence of crucial portions of the conducting system of the heart. $^{3-4}$ Recently, attention has been drawn to the association of congenital heart block with maternal systemic lupus erythematosus, although not on a familial basis. ${ }^{5}$ Antenatal damage to the conducting system by transferred maternal factors may be the mechanism.

Although hydrops fetalis has often been described in association with congenital cardiac malformations, its occurrence with rhythm disorders is rare. Several cases of supraventricular tachycardia in utero have lasted from weeks to months without the development of congestive cardiac failure until after birth. ${ }^{6}$ This has been ascribed to the low in utero systemic 
resistance which increases after loss of the placental circuit at birth. Intrauterine congestive heart failure with gross oedema at birth and supraventricular tachycardia has however been described. ${ }^{7}$ Likewise hydropic appearances at birth associated with congenital heart block have only rarely been described, ${ }^{5}$ congestive failure usually occurring after birth and being attributed to alterations in systemic vascular resistance.

In the siblings described, it is reasonable to assume that the aetiology of the congenital heart block was similar. Echocardiographic examination of both infants was normal. Both had normal Hb levels with no evidence of haemolysis, and their mother at no time had any evidence of a connective tissue disorder.

Rhythm disorders in the fetus, whether tachycardia or bradycardia, are rarely associated with hydrops fetalis, even when of several months' duration. In the infants described, only one developed hydrops, this one being the least severely affected in terms of bradycardia. It is suggested that the gross oedema seen in the second infant at birth was a disorder of serum osmolality occurring secondarily to the disease process which produced the familial congenital heart block, rather than the direct result of congestive cardiac failure in the fetus.

\section{References}

1 Morquio L. Sur une maladie infantile et familiale characterisée par des modifications permanentes du pouls, des attaques syncopales et epileptiformes et la mort subite. Arch Med Enfants 1901 ; 4: 467-75.

2 Michaelsson M, Engle M A. Congenital complete heart block. An international study of the natural history. Cardiovasc Clin 1972; 4: 85-101.

3 Lev M, Caudros H, Paul M H. Interruption of the atrioventricular bundle with congenital atrioventricular block. Circulation 1971 ; 43: 703-10.

4 Lev M. Pathogenesis of congenital atrioventricular block. Prog Cardiovasc Dis 1972; 15: 145-57.

5 Hardy J D, Solomon S, Banwell G S, Beach R, Wright V, Howard F M. Congenital complete heart block in the newborn associated with maternal systemic lupus erythematosus and other connective tissue disorders. Arch Dis Child 1979; 54: 7-13.

- Ferrer P L. Arrhythmias in the neonate. In: Roberts N K, Gelband $\mathrm{H}$, eds. Cardiac arrhythmias in the neonate, infant, and child. New York: Appleton-Century-Crofts, 1977.

7 Silber D L, Durnin R E. Intrauterine atrial tachycardia associated with massive edema in a newborn. Am $J$ Dis Child 1969; 117: 772-6.

8 Altenburger K M, Jedziniak M, Roper W L, Hernandez I. Congenital complete heart block associated with hydrops fetalis. J Pediatr $1977 ; 91$ : 618-20.

Correspondence to Dr R W I Cooke, Institute of Child Health, Alder Hey Children's Hospital, Eaton Road, Liverpool 12 2AP.

\title{
Effect of parental head circumference on that of the newborn child
}

\author{
JOHN OSBORNE, S HAVALAD, B HUDSON, AND A HUGHES \\ Department of Paediatrics, Southmead Hospital, and Department of Community Health, Bristol
}

SUMMARY The head circumferences of 74 term, normal babies were measured, together with the head circumferences of their parents. Maternal head circumference had a significant effect on that of the newborn infant but paternal head circumference had not. An equation is given for estimating the expected head circumference of a newborn infant, provided the birthweight and maternal head circumference are known.

The effects of gender and gestational age on head circumference in infancy have been studied, and charts have been produced allowing for these variations. ${ }^{1}$ Head circumference can also be affected by birthweight, severe intrauterine growth retardation, or congenital abnormality. ${ }^{2}$ Head shape influences head circumference as does moulding for the first 36 hours of life. ${ }^{3}$ It has been suggested that parental head size can account for some of the variation in head size of babies. ${ }^{4}$ In this study this possibility was examined.

\section{Subjects and methods}

74 newborn infants and their parents were studied. Each baby was weighed at birth on two separate scales by two different pairs of nurses to avoid errors. Head circumference was measured by two of us ( $\mathrm{J} \mathrm{O}$ and S H) between 48 and 120 hours of life when the effect of moulding had disappeared. ${ }^{3}$ Gestational age was assessed from the date of the mother's last menstrual period as given at booking. The parents' head circumferences were measured by one of us $(\mathrm{B} \mathrm{H})$ with a fibreglass tape. Disposable paper tapes were used for the babies. The accuracy 